\title{
O SEQUESTRO INTERNACIONAL DE CRIANÇAS E A PROTEÇÃO AOS INTERESSES DO MENOR: A INTEGRAÇÃO DA CRIANÇA A NOVO MEIO COMO EXCEÇÃO À APLICAÇÃO DA CONVENÇÃO DA HAIA DE 1980
}

\author{
THE INTERNATIONAL CHILD ABDUCTION AND THE PROTECTION OF \\ MINORS INTERESTS: THE INTEGRATION OF THE CHILD TO THE NEW \\ ENVIRONMENT AS AN EXCEPTION TO THE APPLICATION OF THE 1980 \\ HAGUE CONVENTION
}

\author{
${ }^{1}$ Artenira da Silva e Silva \\ ${ }^{2}$ João Bruno Farias Madeira
}

\section{RESUMO}

O sequestro internacional de crianças e a proteção aos interesses do menor são temas adstritos à Convenção da Haia de 1980. Embora seja regra a obrigatoriedade de retorno imediato do menor transferido ou retido ilicitamente para o país de sua residência habitual, acentua-se que existem exceções na Convenção, nos artigos 12, 13 e 20, em que esta norma imperativa não se coaduna com o bem-estar do menor. Dentre as exceções prescritas, destaca-se o artigo 12, parágrafo segundo, do texto convencional, o qual estabelece que a ordem do retorno poderá ser negada se a criança estiver adaptada ao novo meio.

PALAVRAS-CHAVE: Sequestro internacional; Criança; Integração; Retorno; Exceção

\begin{abstract}
The international child abduction and the interests of the child protection issues are assigned in the Hague Convention of 1980. Although the rule of immediate return of the illegally retained or illegally transfered child or to the country of their habitual residence, it is emphasized that there are exceptions the Convention, in articles 12, 13 and 20. Considering these articles that mandatory rule is inconsistent with the child's welfare. Among the prescribed exceptions, there is article 12 , second paragraph, from conventional text, which states that the return order may be denied if the child is adapted to the new environment.
\end{abstract}

KEYWORDS: International abduction; Child; Integration; Return; Exception

\footnotetext{
${ }^{1}$ Pós-doutora em Psicologia e Educação pela Universidade do Porto - UP, (Portugal). Doutora em Saúde Coletiva pela Universidade Federal da Bahia - UFBA, Bahia, BA, (Brasil). Docente e pesquisadora do Mestrado em Direito e Instituições do Sistema de Justiça da Universidade Federal do Maranhão - UFMA, Maranhão, MA, (Brasil). E-mail.: artenirassilva@hotmail.com.

${ }^{2}$ Mestrando em Direito e Instituições do Sistema de Justiça pelo Programa de Pós-Graduação em Direito da Universidade Federal do Maranhão - PPGDIR/UFMA, Maranhão, MA, (Brasil). Especialista em Direito e Comércio Internacio (UAU). Professor de Direito Internacional do Instituto Florence de Ensino Superior - IFES, Espírito Santo, ES, (Brasil). Analista Judiciário do Tribunal de Justiça do do Maranhão - TJMA, Maranhão, MA, (Brasil). E-mail.: jbfmadeira@gmail.com.
}

Revista Brasileira de Direito Internacional le-SSN: 2526-0219| Curitiba | v. 2 | n. 2 | p. 39 - 60 | Jul/Dez. 2016. 


\section{INTRODUÇÃO}

O presente artigo se propõe a abordar o tema do rapto internacional de crianças, analisando as situações em que o mesmo é cometido por um dos genitores do infante. Buscase examinar a referida temática com ênfase na exceção à obrigação de retorno do menor prevista no artigo 12, parágrafo segundo, da Convenção da Haia de 1980, a qual aduz que a autoridade judicial ou administrativa, mesmo quando presentes os requisitos convencionais que impõe o retorno do menor a seu país de origem, não deverá ordenar esse regresso se a criança já se encontrar integrada ao novo meio social.

A preocupação com essa abordagem se justifica a luz de um fenômeno ressoante: a globalização, que traz consigo, tanto a facilidade de circulação de pessoas além-fronteira, quanto a disseminação de novas formas de relacionamento entre indivíduos de nacionalidades diversas, ocasionando matrimônios e uniões multiculturais. Com a dissolução de tais relacionamentos, é cada vez mais comum que um dos progenitores, ao possuir nacionalidade diversa da do local de residência do casal, subtraia a prole, sem a anuência do outro genitor, para país diferente do que consta no assento de nascimento da criança ou para local distinto do domicílio familiar, gerando problemas de natureza pessoal e jurídica.

Nesse contexto, a Convenção sobre os Aspectos Civis do Sequestro Internacional de Crianças, internalizada no ordenamento jurídico brasileiro através do Decreto ${ }^{\circ}$. 3.413 , de 14 de abril de 2000, surge como um diploma normativo propenso a solucionar o imbróglio atravessado pelo genitor abandonado que possui o direito de guarda e enfrenta uma série de dificuldades para reaver a guarda do menor. A Convenção em referência, também nominada de Convenção da Haia de 1980, dispõe-se a resolver o problema do sequestro internacional de crianças, partindo da premissa de que a regra a ser observada para por fim ao impasse seria a devolução do menor ao local de sua residência habitual.

O que se pretende ponderar, no entanto, é que essa regra de regresso do impúbere a seu domicílio anterior, estampada logo no artigo $1^{\circ}$ da Convenção da Haia de 1980 , nem sempre tem caráter absoluto ou guarda pertinência com o caso concreto. A hipótese levantada é de que o retorno do infante a seu domicílio originário nem sempre é a opção que melhor lhe resguarda o bem-estar e lhe preserva nas esferas física e psíquica, ou mesmo lhe assegura o direito de manifestação de interesse quando já possui maturidade suficiente para ter a sua opinião considerada em tão delicado assunto familiar.

Discute-se, assim, se as previsões contidas nos artigos 12, 13 e 20 da Convenção da

Revista Brasileira de Direito Internacional le-SSN: 2526-0219| Curitiba | v. 2 | n. 2 | p. 39 - 60 | Jul/Dez. 2016. 
Haia de 1980 não proporcionariam certa relativização a uma aplicação estanque da regra de retorno imediato do menor. Aborda-se, em especial, a exceção prevista no artigo 12, parágrafo segundo, desse diploma legal, buscando-se problematizar até que ponto o retorno imediato da criança seria um princípio absoluto quando levado em consideração o atendimento ao melhor interesse da criança. Para essa consecução, também se utiliza da análise de casos práticos de subtração internacional de infantes pelos pais, com base na jurisprudência dos tribunais brasileiros - notadamente, no Superior Tribunal de Justiça - com o fito de propiciar a busca por uma solução que melhor atenda a demanda posta.

O alicerce central da pesquisa é, portanto, a discussão acerca da cogência da regra de retorno imediato da criança, a qual, propõe-se, seja observada juntamente com as exceções elencadas na Convenção da Haia de 1980, a fim de que os órgãos julgadores decidam de modo favorável ao bem-estar do infante. Como reflexo, o objetivo desta investigação é esclarecer as exceções estabelecidas na Convenção estudada, precipuamente a situada em seu artigo 12, parágrafo segundo, de maneira a evidenciar a sua compatibilidade com a regra geral de retorno imediato do menor ao país de sua residência habitual e testar a hipótese de que nem sempre o retorno imediato do impúbere atende ao princípio do melhor interesse da criança.

No que tange à metodologia empregada, é baseada em um enfoque iminentemente qualitativo e no método dedutivo-dialético, o qual consiste em um entendimento com sentido interpretativo em que são constituídas tentativas de pensamentos universalizantes a partir da construção de teses e antíteses, de modo alternado, visando-se encontrar uma síntese satisfatória. A análise bibliográfica é feita, por sua vez, com base em doutrina, em jurisprudência nacional e internacional e, em especial, nos artigos da própria Convenção sobre os Aspectos Civis do Sequestro Internacional de Crianças.

\section{O SEQUESTRO INTERNACIONAL DE CRIANÇAS E A CONVENÇÃO DA HAIA DE 1980}

A Convenção sobre os Aspectos Civis do Sequestro Internacional de Crianças foi assinada em Haia, Holanda, em 25 de outubro de 1980, e encontra-se ratificada em noventa e quatro países, dentre eles o Brasil ${ }^{3}$, já tendo cooperado para a solução de diversos casos de

\footnotetext{
${ }^{3}$ O Brasil ratificou a Convenção somente vinte anos após a sua criação, através do Decreto no 3.413 , de 14 de abril de 2000.
}

Revista Brasileira de Direito Internacional le-SSN: 2526-0219| Curitiba | v. 2 | n. 2 | p. 39 - 60 | Jul/Dez. 2016. 
subtração ou retenção indevida de menores ${ }^{4}$. O texto convencional tem por escopo o combate à transferência ou retenção ilícita do infante em país diferente daquele em que habitualmente reside, tendo por premissa ocasionar o bem-estar da criança, uma vez que resguarda o direito dela permanecer inserida no lugar com o qual está afeita.

Antes da vigência da Convenção da Haia de 1980, a maior parte das ocorrências de subtração de crianças era feita pelos genitores do sexo masculino. Em situação não infrequente, o pai acreditava, como represália à concessão da guarda do menor à mãe, que o melhor seria levar o infante para país distinto do lugar de sua residência habitual, subtraindoo. Entretanto, esse contexto tem sofrido alterações na medida em que a mãe também se torna parte ativa desse comportamento, fugindo com o menor por motivos variados, que vão desde o sofrimento de violência doméstica e familiar à busca por melhores oportunidades de trabalho, dando início a uma verdadeira disputa pela custódia da criança.

Nessa conjuntura, Dolinger (2003, p. 241) menciona as dificuldades que o genitor abandonado enfrentava para recuperar o menor antes da ratificação da Convenção:

\begin{abstract}
Até 1980, ano de aprovação da Convenção de Haia, as dificuldades para se recuperar uma criança sequestrada eram praticamente insuperáveis. Primeiro, porque para localizar uma criança, cujo paradeiro era desconhecido, exigia-se um longo processo de investigação no qual a parte não tinha o apoio das autoridades do local onde acreditava estar a criança. Depois, ao se localizá-la, o interessado haveria de ingressar no juízo local, que iniciaria um processo para averiguar o estado em que se encontrava a criança, que, com o decorrer dos anos, acabava por decidir pela não devolução, por mais irregular que tivesse sido o seu deslocamento.
\end{abstract}

Araújo (2011, pp. 553-554) comenta de maneira suplementar a questão, reafirmando a importância da Convenção para solver esse embate entre genitores:

\begin{abstract}
Presumia-se que depois que a criança fosse restituída para outro país, jamais retornaria. Isso gerou grande sensação de frustração dos envolvidos nos sistemas jurídicos estrangeiros. Não havia nenhum instrumento em prol da cooperação entre os poderes judiciários e a exceção de ordem pública assumiu um papel preponderante na maioria dos julgamentos.
\end{abstract}

A Convenção da Haia sobre os Aspectos Civis do Sequestro Internacional de Crianças veio, portanto, como instrumento para combater essa prática unilateral de retirada do menor de seu domicílio por seu genitor e para impedir que os obstáculos estabelecidos pelos Estados acabassem por concretizar essa condição de retenção ilícita. Desse modo, instituiu que o foro competente para analisar os litígios sobre a guarda do infante seria, a princípio, o local de sua residência habitual, de maneira que a remoção da criança sem a anuência do progenitor que possuísse o direito de guarda seria considerada ilícita e as decisões judiciais

4 Nesse sentido, REsp 1214408/RJ, REsp 1196954/ES, REsp 1293800/MG, REsp 1315342/RJ, REsp 1239777/PE, todos do Superior Tribunal de Justiça.

Revista Brasileira de Direito Internacional le-SSN: 2526-0219| Curitiba | v. 2 | n. 2 | p. 39 - 60 | Jul/Dez. 2016. 
sobre o mérito de guarda seria matéria exclusiva das autoridades do Estado requerente.

Trata-se, assim, de uma recomendação ao Estado requerido, instituída no artigo 16 da Convenção de 1980, que tem por objetivo evitar que as autoridades judiciais do Estado para o qual foi subtraída a criança sejam utilizadas pelo genitor subtrator para dar um aspecto de legitimidade à conduta do deslocamento ou retenção ilícita. Razão essa que merece ser interpretada como determinação convencional de regresso do menor à jurisdição mais adequada a apurar os direitos de guarda e visita a si correlatos, conforme acentua Sifuentes (2011, p. 137):

\begin{abstract}
Não se trata, como erroneamente se supõe, de devolvê-la ao outro genitor, mas de encaminhá-la à autoridade competente, pois é ali que a criança tinha a sua vida, o seu círculo de amizades, a escola, a vizinhança. O juiz ou a autoridade local dispõem, sem dúvida, de melhores meios para colher provas e avaliar qual dos pais deve exercer o direito de guarda.
\end{abstract}

Insta esclarecer, no entanto, que a Convenção não busca decidir qual progenitor deverá obter a guarda do menor no caso concreto, mas procura remeter a criança à autoridade competente para que esta decida sobre o mérito em questão. Até mesmo porque o objetivo do referido tratado internacional não é rediscutir o direito de guarda já afirmado no campo da Justiça de Família, e sim lidar com a transferência ${ }^{5}$ e com a retenção ${ }^{6}$ ilícitas de crianças em local distinto do de sua residência habitual, naquilo que se convencionou nominar, no Brasil, de sequestro internacional.

Apesar do termo sequestro, adotado na tradução brasileira da Convenção da Haia de 1980 como interpretação da palavra abduction (abdução, em inglês), a expressão não se refere propriamente ao crime de sequestro tipificado no artigo 148 do Código Penal Brasileiro, não estando ligada à subtração de pessoas com a finalidade de conseguir dinheiro ou benefício financeiro. Trata-se não tecnicamente de sequestro, e sim de um deslocamento ilegal da criança de seu país ou da retenção indevida em outro local que não o de sua residência habitual, onde o genitor-sequestrador acredita que tal situação atenda melhor seus interesses.

Outro termo que também merece detimento com via a proporcionar uma interpretação mais coadunada com a ideia de sequestro internacional adotada pela Convenção da Haia de 1980 é o conceito de direito de guarda. O texto convencional possui

\footnotetext{
${ }^{5}$ A transferência ilícita ocorre quando um dos genitores desloca a criança para um país distinto do de sua residência habitual.

${ }^{6}$ A retenção ilícita acontece quando, embora a criança tenha sido transferida de forma legítima para outro local, o seu retorno ao país é impedido por meio da ação do taking parent (termo utilizado na Convenção da Haia de 1980 para se referir ao genitor que subtraiu a criança para um país distinto do local de sua residência habitual, violando os direitos de guarda do genitor abandonado).
} 
conceito próprio para se referir ao direito em questão, que não coincide necessariamente com os conceitos que estão dispostos no ordenamento jurídico dos Estados Contratantes, a teor do que explicitam Mônaco e Rodas (2013, p. 311):

[...] o direito de guarda pressupõe, segundo disposição da Convenção, o direito de fixar a residência habitual da criança. Assim, se o genitor guardião decidir deixar o Estado onde tem a sua residência habitual, para outro Estado, haverá alteração, consequentemente, da residência habitual da criança. Nesse caso, o genitor não guardião não poderá reclamar o retorno da criança ao Estado de sua residência habitual, a menos que também ele seja, de fato ou de direito, detentor da guarda.

Assim, o genitor que possui a guarda unilateral também possuirá o direito de fixar a residência habitual do infante, porém não poderá ele cercear o direito de visitação do outro genitor que não detém a guarda. Já quanto à possibilidade de observação do direito em comento nas hipóteses de guarda compartilhada, Mônaco e Rodas (2013, p. 310) dispõem:

[...] quando ambos os pais possuem a guarda de forma conjunta, nenhum deles poderá deslocar-se para outro território em companhia da criança, sob pena de configurar a subtração internacional, salvo na hipótese de ter havido acordo de vontades consubstanciado na autorização de deslocamento da criança.

Desta forma, quando configurada a retirada da criança do seu local de residência habitual por um dos genitores, sem a anuência do outro, na vigência da guarda compartilhada, tal ação caracterizar-se-á como transferência ilícita do menor. Logo, ocorrerá conduta tutelável pela Convenção na hipótese de remoção do menor sem a aceitação expressa do outro genitor em guarda compartilhada. Fato esse que dá direito ao genitor abandonado de exigir, com base no artigo $1^{\circ}$, "o retorno imediato de crianças ilicitamente transferidas para qualquer Estado Contratante ou nele retidas indevidamente" (BRASIL, 2000, sem paginação).

\section{OS REQUISITOS PARA A APLICAÇÃO DA CONVENÇÃO DE 1980}

Para que sejam cumpridas as regras estabelecidas na Convenção da Haia de 1980 e se possa dar azo ao objetivo de proteção do interesse do menor, existem determinações a serem seguidas, com fulcro no artigo $4^{\circ}$ da Convenção, que servem como balizadoras dos requisitos expressos de sua aplicação:

Art. $4^{\circ}$. A Convenção aplica-se a qualquer criança que tenha residência habitual num Estado Contratante, imediatamente antes da violação do direito de guarda ou de visita. A aplicação da Convenção cessa quando a criança atingir a idade de dezesseis anos (BRASIL, 2000, sem paginação).

Nesse diapasão, a autoridade julgadora deverá observar quatro pontos fundamentais para a subsunção do pleito do genitor abandonado à Convenção sobre os Aspectos Civis do 
Sequestro Internacional de Crianças: (a) os Estados envolvidos no pedido de retorno do menor devem fazer parte da Convenção, ou seja, devem ter assinado e ratificado esse documento previamente; (b) a criança deve, em momento anterior ao rapto internacional, possuir residência habitual no Estado requerente; (c) a transferência ou retenção ilícita deve violar, ao tempo do sequestro, o direito de guarda ou de visita de um dos genitores; e (d) a criança deve ter a idade limite de dezesseis anos incompletos para que seja alvo dessa proteção.

A respeito do primeiro requisito, cabe assentar, com base no artigo $2^{\circ}$, item 1 , alínea $a$ da Convenção de Viena sobre o Direito dos Tratados, de 1969, que um tratado internacional concluído entre Estados demanda, para a sua exigência, a observância de algumas etapas em seu processo de elaboração, com o intuito de gerar efeitos para os celebrantes. Esse processo de elaboração do tratado, que se inicia com a negociação, não se encerra com a simples assinatura $^{7}$ - etapa na qual o Estado expressa sua anuência preliminar ao termo pactuado mas se aperfeiçoa com a ratificação ${ }^{8}$ - etapa na qual o ente soberano exprime a sua vontade em obrigar-se por suas normas - e com a promulgação e publicação de seu texto.

Ao aderir a uma Convenção, o Estado-Parte fica compelido a cooperar com as solicitações dos demais Estados signatários, tendo em vista que, concluídas as etapas de promulgação e publicação, restará atestada a existência de um tratado ratificado pelo Estado e será determinada a pronta execução em seu território. Isso importa dizer que, tanto os signatários originários da Convenção da Haia de 1980, quanto os que posteriormente vierem a aderi-la são por ela responsáveis em direitos e obrigações, e que, se determinado Estado não for membro da Convenção e ocorrer um caso de subtração internacional de criança dentro das suas fronteiras, este poderá recusar-se a oferecer cooperação jurídica internacional.

No que tange, por sua vez, ao requisito da efetiva residência habitual da criança no Estado requerente, a Convenção da Haia sobre os Aspectos Civis do Sequestro Internacional de Crianças não define, em seu texto, o termo de modo explícito. Nem se pode tomar por conceito de residência habitual a definição de domicílio que se encontra na legislação lex fori, pois a Convenção tem como objetivo a uniformização de procedimentos e o conceito em vislumbre não alcança uniformidade no direito comparado. Dessa sorte, a abordagem do assunto necessita observar o contexto fático envolvido, tomando-se como referência a análise

\footnotetext{
${ }^{7}$ No Brasil, qualquer autoridade que detenha a carta de plenos poderes emitida pelo Presidente da República e assinada pelo Ministro das Relações Exteriores poderá assinar o ato internacional, não implicando tal assinatura em obrigação ao Estado de aceitar o conteúdo do tratado em definitivo.

${ }^{8}$ No Brasil, a ratificação é um ato privativo do Presidente da República, estando sujeita à autorização parlamentar na hipótese em que acarretar encargo ou compromisso gravoso ao patrimônio nacional.
}

Revista Brasileira de Direito Internacional le-SSN: 2526-0219| Curitiba | v. 2 | n. 2 | p. 39 - 60 | Jul/Dez. 2016. 
das perspectivas do menor, dos genitores e outros subsídios correlatos.

Sobre esse ponto, Miguel Filho (2010, p. 55) consigna que, em razão da Convenção não definir residência habitual, “caberá ao magistrado, após a apreciação das circunstâncias fáticas e jurídicas do caso concreto, decidir qual o local da residência habitual do menor". Essa fixação mostra-se de importância salutar na medida em que a definição da residência habitual do impúbere traz reflexos diretos para a designação de qual o juízo competente para julgar o direito de guarda, a ponto do Superior Tribunal de Justiça enunciar, para o contexto brasileiro, o seguinte entendimento no Recurso Especial 1315342/RJ:

A residência habitual, para fins da Convenção de Haia é aquela em que a criança
tinha as suas raízes, estava vivendo em caráter de permanência. E, segundo a
referida Convenção, é a Lei desse Estado soberano que deve decidir as questões
relativas à guarda dos menores (REsp 1315342/RJ, Rel. Ministro Napoleão Nunes
Maia Filho, primeira turma, julgado em 27/11/2012, DJe 04/12/2012; ponto n. 9 da
ementa).

Com isso, buscou-se não definir o conceito de residência habitual conforme o termo utilizado no direito interno. Utilizando-se da Convenção da Haia de 1980, o Superior Tribunal de Justiça conceituou residência habitual, de modo sucinto, como o local diferente do país de retenção do menor, não correspondendo, assim, tal designação ao conceito de residência imbricado no ordenamento brasileiro.

A seu turno, no que diz respeito ao requisito da violação dos direitos de guarda e visita exigido como terceiro critério expresso para a utilização da Convenção da Haia sobre os Aspectos Civis do Sequestro Internacional de Crianças, resta destacar, em face das ponderações já realizadas no tópico anterior, apenas a distinção entre os institutos de guarda e visita feita no artigo $5^{\circ}$ do diploma convencional:

Art. $5^{\circ}$. Nos termos da presente Convenção:

a) o 'direito de guarda' compreenderá os direitos relativos aos cuidados com a pessoa da criança, e, em particular, o direito de decidir sobre o lugar da sua residência;

b) o 'direito de visita' compreenderá o direito de levar uma criança, por um período limitado de tempo, para um lugar diferente daquele onde ela habitualmente reside (BRASIL, 2000, sem paginação).

Para que o genitor abandonado possa requerer o pedido de retorno da criança, deverá provar, portanto, que foi violado o seu direito de cuidado com o menor - direito de guarda - ou que houve abuso do direito do outro genitor de levar a criança por um período limitado de tempo - direito de visita.

O último requisito a ser observado compreende a idade limite do menor, estabelecida pela Convenção para a fruição de seus efeitos. Tendo em vista que a mesma tipifica como 
criança o indivíduo que possui idade inferior a dezesseis anos de idade, cessará a sua aplicação quando o menor atingir essa idade limite. Aliás, Tiburcio e Calmon (2014, p. 96), trazendo alguma crítica ao parâmetro estabelecido, dispõem:

Dessa forma, nem todas as crianças, estão abrangidas pelo Convênio de 1980, que optou por uma idade-limite mais baixa do que as de outros textos organizados pela Conferência Permanente de Direito Internacional Privado da Haia, por entender que os maiores de 16 anos já possuem relativa maturidade, devendo ter sua vontade respeitada tanto pelos seus genitores quanto pelos próprios magistrados.

Destarte, embora à legislação brasileira conceitue o termo criança como pessoa que possua até doze anos de idade incompletos e adolescentes os que possuam entre doze e dezoito anos de idade - segundo o artigo $2^{\circ}$ da Lei $\mathrm{n}^{\circ} 8.069$ (Estatuto da Criança e do Adolescente), a Convenção da Haia de 1980 determina que a sua aplicação alcance apenas o menor que não ultrapassou a idade de dezesseis anos, pouco importando saber se a instauração do procedimento para o retorno do menor tenha se dado em momento anterior ao atingimento dessa idade-limite 9 (TIBURCIO; CALMON, 2014, p. 108).

Somados a esses quatro requisitos, expressos, como visto, no artigo $4^{\circ}$ da Convenção da Haia de 1980, ainda existem outras condições de aplicação do texto convencional que se encontram distribuídos de forma esparsa no referido diploma e que exigem uma maior atenção exegética em sua construção: (a) o Estado requerido está proibido de processar ou julgar matéria referente à guarda do menor durante a vigência de impasse de sequestro internacional de criança - artigo 16, primeira parte; (b) a comunicação da transferência ou retenção ilícita deverá ocorrer dentro de prazo razoável de tempo ${ }^{10}$ - artigo 16 , segunda parte; e (c) o princípio do melhor interesse da criança deverá ser observado - preâmbulo.

Dentre os requisitos esparsos, é relevante pontuar que o princípio do melhor interesse da criança é o arquétipo estruturante de toda a Convenção, a ponto do preâmbulo desse acordo internacional prever que "os interesses da criança são de primordial importância em todas as questões relativas à sua guarda, desejando proteger a criança no plano internacional, dos efeitos prejudiciais resultantes de mudança de domicílio ou de retenção ilícita" (BRASIL, 2000, sem paginação).

Não obstante a ideia deste princípio encontrar amparo, tanto no preâmbulo, quanto no artigo $1^{\circ}$ da Convenção de Haia de 1980, o conceito de melhor interesse da criança não

\footnotetext{
${ }^{9}$ Ao ultrapassar o limite de idade estabelecido pela Convenção, a aplicação convencional cessa, devendo o caso ser encaminhado para a Vara de Família a fim de que seja dado regular prosseguimento.

${ }^{10}$ Embora a Convenção de Haia de 1980 não tenha deixado claro, aparentemente, o que considera como período razoável de tempo, o artigo 12 da referida norma estabelece o prazo máximo de um ano para marcar o início do pleito de retorno do menor, impondo, inclusive, o regresso imediato nesses casos.
}

Revista Brasileira de Direito Internacional le-SSN: 2526-0219| Curitiba | v. 2 | n. 2 | p. 39 - 60 | Jul/Dez. 2016. 
possui definição expressa no diploma convencional. Entretanto, o mesmo é claro ao estabelecer aos Estados-Partes que os interesses das crianças devem ser pautados sob a égide de seu bem-estar, sobrepondo-se, inclusive, aos interesses dos pais. Essa busca pelo bem-estar da criança, presente na Convenção, justifica a persecução pela manutenção de seus laços de afeto com a figura de seus progenitores, de maneira a que se assegure a não interrupção de tais laços promovedores do bem-estar psíquico do menor.

\section{AS EXCEÇÕES À APLICAÇÃO DA CONVENÇÃO DE 1980}

A Convenção da Haia de 1980, apesar de consagrar a regra de retorno imediato do infante no exato teor dos requisitos esmiuçados no tópico anterior, também legitima certas exceções quanto à obrigação que os Estados-Partes assumiram de garantir o regresso imediato de menores transferidos ou retidos ilicitamente. Essas exceções são expressões do princípio do melhor interesse da criança, constituindo um rol de critérios a ser observado quando da execução da regra de retorno da criança ao seu lugar de residência habitual.

A Convenção da Haia de 1980 estabelece, em seus artigos 12, 13 e 20, hipóteses em que retorno da criança transferida ou retida de forma ilícita poderá deixar de ocorrer. A primeira delas, prevista no artigo 12, em seus parágrafos primeiro e segundo, admite que, em se passando mais de um ano entre a data de transferência ou retorno do infante e a data da abertura do processo perante a autoridade judicial do Estado onde o menor se encontra, o pedido poderá ser negado, inclusive se restar comprovado que a criança já está adaptada ao novo meio.

Transcorrido, portanto, o prazo de um ano entre a data do rapto e a data de início do processo, surge a obrigação da autoridade do Estado de refúgio determinar o retorno imediato do menor. Haverá, assim, de acordo com o parágrafo primeiro do artigo 12, a obrigação de ordenar o retorno do infante sempre que configurado esse lapso inferior a um ano, sem possibilidade de argumentação ou investigação sobre a possível adaptação da criança no Estado de refúgio. Sendo assim, na letra estreita da Convenção, estariam impedidas as autoridades do Estado de refúgio, em se tratando de sequestro internacional de crianças ocorrido dentro do prazo de menos de um ano, admitir argumentos sobre a possível adaptação do menor à localidade em que passou a residir.

No que tange ao segundo parágrafo do artigo 12, percebe-se que o retorno poderá não ser admitido nos casos em que a criança encontrar-se adaptada ao novo meio, em razão de 
ter passado longo período no Estado de refúgio. Trata-se de hipótese que, pela literalidade do texto convencional, refere-se às situações em que o intervalo de tempo entre o sequestro e o pedido de regresso tenha excedido prazo de um ano, já que ausente o termo imediato indicado na acepção anterior. A distinção entre os parágrafos que compõem o artigo 12 é, pois, bastante óbvia: o parágrafo primeiro não apresenta nenhuma alusão quanto à adaptação da criança, ao passo que o parágrafo segundo ressalta uma exceção à regra, pois o retorno imediato do menor poderá ser negado com a prova de integração da criança ao novo meio.

Por fim, o parágrafo terceiro do artigo 12 prescreve uma regra suplementar, voltada à hipótese de suspensão ou extinção do processo do pedido de retorno caso o Estado requerido tenha motivos para acreditar que o infante esteja submetido à jurisdição de outro Estado-Parte da Convenção. Essa percepção deverá ser analisada em reciprocidade com o artigo $9^{\circ}$ da Convenção, o qual afirma que, quando a Autoridade Central que recebeu o pedido mencionado tiver razões para acreditar que a criança se encontra em outro Estado Contratante, deverá transmitir o pedido, diretamente e sem demora, à Autoridade Central desse Estado Contratante.

O segundo artigo que trata das hipóteses de exceção ao retorno do menor é o artigo 13. Em seu parágrafo primeiro, alínea $a$ evidencia que não há obrigação em ordenar a restituição da criança ao requerente se este não exercia de maneira efetiva os cuidados com a pessoa da criança na época da transferência ou retenção ou quando consentiu ou concordou, subsequentemente, à condição que desejava pugnar.

A primeira hipótese elencada na referida alínea é, portanto, clara: a Convenção somente permitirá o retorno para se fazer cumprir os direitos de guarda existente na época da retenção ou transferência ilícita. A Convenção ordena à autoridade judicial ou administrativa averiguar a situação fática anterior à remoção ou retenção ilícita do menor com escopo de verificar se o direito de guarda estava sendo praticado de forma efetiva ${ }^{11}$. Caso se prove que o genitor abandonado não exercia o direito de guarda efetivamente, resta comprovado que a subtração do menor não ocorreu de forma ilícita e, consequentemente, configura-se uma das hipóteses de exceção ao retorno da criança.

A segunda hipótese expressa na mesma alínea refere-se à existência de consentimento ou concordância do requerente com o rapto da criança. Trata-se de situação

\footnotetext{
${ }^{11}$ A comprovação quanto ao não exercício efetivo da guarda caberá ao genitor sequestrador, impondo-lhe o ônus de prová-lo conforme o direito do local de residência habitual do menor, dependendo tal alegação da discricionariedade do Estado de refúgio.
}

Revista Brasileira de Direito Internacional le-SSN: 2526-0219| Curitiba | v. 2 | n. 2 | p. 39 - 60 | Jul/Dez. 2016. 
complexa em que se discute a prova do consentimento dado pelo genitor abandonado, uma vez que existem ocorrências no qual o menor sai do local de residência habitual com sua concordância. Em tais casos, um ponto importante a ser observado é a verificação da forma que a criança foi levada do país de sua residência habitual. Analisa-se, por exemplo, se foi dada uma autorização de viagem de férias ao menor ou se a viagem não conta com qualquer autorização formal por parte do genitor abandonado, de modo que, neste último caso, poderá haver indícios de que o translado ocorreu de forma ilícita.

Já na alínea $b$ do parágrafo segundo do artigo 13, encontram-se as exceções em que é levado em consideração, especificamente, o melhor interesse da criança, como no caso de o impúbere não ser afastado do local de residência habitual sem a segurança de não estar sujeito a perigo físico ou psíquico, ou inserido em uma situação intolerável. Nesse tocante, o retorno deverá ser negado se configurada alguma condição que traga prejuízos ao menor. Situação essa que autoriza o órgão julgador do Estado de refúgio do infante a tomar a decisão que atenderá o princípio do melhor interesse da criança.

De acordo com esse raciocínio, devem ser analisadas as circunstâncias de existência de risco grave de perigo de ordem física ou psíquica ou situação intolerável para o menor em relação ao local em que o infante terá melhores oportunidades de vida. Ademais, o risco em questão deve ser grave, não bastando a mera existência do risco. Ele tem que ser relevante, impondo-se observar o tamanho do risco para que se possa afastar a possibilidade do retorno da criança ao país de residência habitual. Tal risco deverá ser apontado e comprovado com fundamentos concretos, cabendo sua prova ao genitor que se opuser à devolução da criança.

Para que seja empregada a exceção disposta no artigo 13, parágrafo primeiro, alínea $b$ como forma restritiva a um caso concreto, devem ser consideradas apenas as hipóteses em que há uma agressão física penalmente relevante ou uma violência psicológica com comprovação de risco psíquico através de perícia profissional. Mormente, deverá haver prova além da constatação do acontecimento de risco grave de ordem física ou psíquica ou qualquer outra situação, exigindo-se a demonstração de que o Estado requente não estaria interessado em tomar todas as providências necessárias para dar proteção integral à criança.

Há que se mencionar a importância, nessa conjuntura, de o menor ser ouvido, de acordo com o artigo 13, parágrafo segundo, da Convenção, em atendimento ao princípio do melhor interesse. Isso em todas as hipóteses em que a criança estiver em adequadas condições psíquicas de se manifestar, impondo-se o dever de ser ouvida acerca de qual medida atenderá 
melhor ao seu bem-estar. Até mesmo porque, embora a Convenção da Haia de 1980 não tenha estabelecido os parâmetros formais para essa oitiva, nada obsta que o juízo do Estado de refúgio possa estabelecê-los diante do caso concreto, a fim de viabilizar uma maior proteção ao menor ${ }^{12}$.

Coadunado a esse propósito, o artigo 12 da Convenção sobre os Direitos da Criança, internalizada no ordenamento jurídico brasileiro através do Decreto $\mathrm{n}^{\circ} .99 .710$, de 21 de novembro de 1990, determina que os Estados-Partes assegurarão à criança que estiver capacitada a formular seus próprios juízos o direito de expressar suas opiniões livremente sobre todos os assuntos a si relacionados, levando-se devidamente em consideração essas opiniões, em função da sua idade e maturidade. Acrescenta que, com tal propósito, se proporcionará à criança a oportunidade de ser ouvida em todo processo judicial ou administrativo que afete a mesma, quer diretamente quer por intermédio de um representante ou órgão apropriado, em conformidade com as regras processuais da legislação nacional.

Retomando, todavia, as exceções previstas na Convenção da Haia de 1980, tem-se que a última norma que aborda o tema da devolução do infante é a regra inserta no artigo 20. Em seu texto, o artigo permite que se negue o retorno do menor quando os princípios fundamentais do Estado requerido não forem compatíveis com relação à proteção dos direitos humanos e das liberdades fundamentais. Trata-se de hipótese que aborda uma norma a ser definida em consonância com a norma interna de cada Estado-Parte, cabendo ao Estado de refúgio provar não apenas a existência de uma incompatibilidade entre seus princípios e os princípios do Estrado requerente, como também demonstrar que existe uma contradição no que tange os princípios protetores dos direitos humanos.

Diferentemente do artigo 13, parágrafo primeiro, alínea $b$, que tem iminente conteúdo jurídico, o artigo 20 aborda questões fáticas de liberdades fundamentais, uma vez que, para determinar o retorno do menor ao país de residência habitual, tais questões deverão ser observadas. No entanto, o artigo 20, na prática, é raramente empregado pelas Cortes nacionais para negar o retorno do infante, pois esta regra se aplica somente a casos excepcionais como, por exemplo, na hipótese em que o país onde o menor tinha a sua residência habitual propicie, em caso de reingresso, a sua sujeição a maus-tratos.

Em verdade, todas essas exceções ao retorno do menor dispostas na Convenção da

${ }^{12}$ Existe um pré-requisito para que seja levada em consideração essa vontade da criança: deverá o menor ter atingido idade e grau de maturidade suficientes. Trata-se, portanto, de requisito de caráter subjetivo e que deve ser verificado na ocasião da avaliação por um profissional a que o menor deverá ser submetido.

Revista Brasileira de Direito Internacional le-SSN: 2526-0219| Curitiba | v. 2 | n. 2 | p. 39 - 60 | Jul/Dez. 2016. 
Haia de 1980 visam atender, diante do caso concreto, ao princípio do melhor interesse da criança. Sempre que não caracterizada nenhuma das hipóteses de exceção que permita a permanência do infante no país de refúgio, o interesse do menor será atendido quando for expedido uma ordem designando o retorno da criança a seu país de residência habitual.

\section{A INTEGRAÇÃO DA CRIANÇA A NOVO MEIO COMO EXCEÇÃo À APLICAÇÃO DA CONVENÇÃO DE 1980}

Dentre as exceções previstas na Convenção da Haia de 1980 voltadas a mitigar a obrigatoriedade compulsória do retorno imediato da criança a seu país de origem, o segundo parágrafo do artigo 12 merece destaque. A referida norma, diferentemente da contida no parágrafo primeiro do mesmo artigo, estabelece o retorno do menor sem fazer qualquer menção ao termo imediato. Isso porque, tendo passado mais de um ano entre o rapto do infante e o pedido de restituição por parte do genitor abandonado, a volta ao status quo ante, intentada com a devolução do impúbere, poderá não ocorrer, caso seja constatado que a criança está adaptada ao novo meio.

Trata-se de verdadeira ressalva à regra de que a autoridade judicial ou administrativa, mesmo quando passados um ou mais anos entre o rapto internacional e o pedido de retorno, deverá ordenar o regresso da criança. Nesse caso, a devolução do menor ao local de sua residência habitual poderá ser recusada se consistir em uma nova revitimização do menor, em estando ele já inserido na realidade social da comunidade em que passou a viver naquele novo país. Tiburcio e Calmon (2014, p. 264), ao discorrerem sobre a prova da adaptação do menor a esse novo ambiente, expõem:

\footnotetext{
Atente-se para o fato de que a prova de efetiva adaptação da criança ao novo ambiente não se satisfaz com a simples demonstração de matrícula da criança em uma boa escola; de habitação em uma moradia confortável; da contratação de babá, ou motorista, para atender o infante; de atendimento médico e hospitalar garantido por um excelente plano de saúde; ou de circunstâncias similares.
}

Nesse pormenor, as autoras defendem que as crianças seriam seres que se adaptariam com maior facilidade ao meio, principalmente em estando na companhia de seus entes queridos. Seria equivocada, assim, uma decisão tomada pelo órgão julgador com base em estandartes de adaptação, tendo em vista que a exceção disposta no artigo 12 mostra necessária a produção de prova pericial e oral, a fim de que se indique o grau de maturidade 
psicológica da criança raptada. Porém, tanto a jurisprudência estrangeira ${ }^{13}$, quanto a nacional $^{14}$ ainda não chegaram a formar critérios objetivos para identificar a idade e o desenvolvimento psicológico ideal para que se possa acolher o mérito da alegação.

Não obstante essa incerteza, fato é que, no cenário brasileiro, o Superior Tribunal de Justiça tem reconhecido a relevância da produção de prova oral e da pericia psicológica nas instâncias de base a fim de equacionar o desejo do impúbere e o seu bem-estar físico e emocional, na medida em que esse menor tem a sua vontade percebida nos autos, em conformidade com o princípio do melhor interesse criança, a teor do aduzido no Recurso Especial 1293800/MG:

A Convenção da Haia sobre os Aspectos Civis do Seqüestro Internacional de Crianças tem como escopo a tutela do princípio do melhor interesse da criança, de modo que nos termos do caput do art. 12 da referida Convenção [...]. De acordo com o REsp 1.239.777/PE, Rel. Min. César Asfor Rocha, a Convenção da Haia, não obstante apresente reprimenda rigorosa ao sequestro internacional de menores com determinação expressa de retorno deste ao país de origem, garante o bem estar e a integridade física e emocional da criança, o que deve ser avaliado de forma criteriosa, fazendo-se necessária a prova pericial psicológica.

Na hipótese dos autos, a ação foi proposta após o prazo de 1 (um) ano a que se refere o art. 12 caput da Convenção. Sendo que o acórdão recorrido, ao reformar a sentença para que a menor permanecesse em solo brasileiro assentou que "diante da constatação no estudo psicológico de que a menor se encontra inteiramente integrada ao meio em que vive e que a mudança de domicílio poderá causar malefícios no seu futuro desenvolvimento -, e do próprio reconhecimento da Autoridade Central Administrativa de que "não seria prudente, portanto, arriscar que ela vivencie uma nova 'ruptura' de vínculos afetivos, especialmente em virtude de sua tenra idade" (três anos à época da avaliação) -, a "interpretação restritiva" dada pelo ilustre Juiz ao art. 12 da Convenção, determinando o imediato regresso à Argentina, quatro anos depois do seu ingresso em solo nacional (hoje conta com seis anos), vai de encontro à finalidade principal da Convenção, que é a proteção do interesse da criança."

Nesse ponto, melhor destino não se revela o recurso, pois a tarefa de apreciar os elementos de convicção e apontar o "melhor interesse da criança" não ultrapassa a instância ordinária, soberana no exame do acervo fático-probatório dos autos (REsp 1293800/MG, Rel. Ministro Humberto Martins, segunda turma, julgado em 28/05/2013, DJe 05/06/2013; pontos n. ${ }^{\circ} 3$ a 6 da ementa).

Essa exceção capitulada no parágrafo segundo do artigo 12 da Convenção da Haia de 1980 elenca, portanto, um óbice ao retorno imediato da criança mediante a prova de sua integração ao meio, a qual deverá ser avaliada, de forma criteriosa, nos moldes declinados pelo acerco probatório indicado pelo Superior Tribunal de Justiça, embora não haja na Convenção ou nos julgados qualquer referência a quem cabe o ônus da prova. Essa necessidade de buscar provar a integração do menor ao meio é de importância substancial para que o órgão julgador decida se a criança está ou não ligada ao Estado de refúgio, de

${ }^{13}$ INCADET, M (A Child) (Abduction: Child's Objections), Re (CA (Civ Div)) Court of Appeal (Civil Division), 27 March 2007.

${ }^{14}$ TRF-2, julg. 16 dez. 2009, Apelação no 2009.51.01.018422-0, Relator Dr. Fernando Marques.

Revista Brasileira de Direito Internacional le-SSN: 2526-0219| Curitiba | v. 2 | n. 2 | p. 39 - 60 | Jul/Dez. 2016. 
maneira que fixar esse aspecto e indicar a quem cabe provar a integração do infante ao meio em que se encontra é parâmetro essencial, a ponto de Pérez-Vera (1981, p. 47) acentuar:

La disposición no precisa en absoluto quién debe probar este extremo; no obstante, parece lógico pensar que esa tarea le corresponde al secuestrador o a la persona que se opone al retorno del menor, sin perjuicio del poder de apreciación de las autoridades internas al respecto. ${ }^{15}$

Segundo a doutrinadora oficial da Convenção da Haia de 1980, o ônus da prova deve recair, dessa forma, sobre a parte que se opõe à devolução, sem prejuízo do poder de apreciação das autoridades locais a esse respeito e sob pena de admitir a procedência do pedido de regresso do infante, devendo todo esse contexto probatório ser examinado de modo a prestigiar a oitiva expressa do menor, nos termos do artigo 12 da Convenção sobre os Direitos da Criança.

No bojo dessa discussão, fato é que a integração da criança ao novo meio deve ser vista com cautela, pois caberá considerar a adaptação do infante ao local em que exerce suas atividades comuns. Assim, por ser uma adaptação a outro país, com a adequação a outro idioma, cultura, pessoas, etc., e estando a criança já capacitada para se expressar no idioma do país de refúgio, o seu regresso imediato poderá causar grande prejuízo ${ }^{16}$.

A Convenção não prevê, aliás, a definição do termo integração. Todavia, pode-se afirmar que o termo em comento consiste, de forma genérica, na negativa do retorno do infante baseada em uma comprovação significante de que o menor se encontra em harmonia com o novo meio, estando ele em segurança e estabilidade. Com essa premissa, tem-se que, embora as decisões tomadas pelo órgão julgador busquem atender, como regra, ao princípio do melhor interesse do menor, a aplicação da referida exceção poderá dar vantagem ao genitor subtrator caso se comprove a integração do menor.

Um primeiro posicionamento acerca dessa discussão, que analisa os meandros de adaptação da criança ao meio e a sua relação com a atuação ilegal do genitor subtrator, pode ser percebida no julgado do Tribunal Regional Federal da $2^{\text {a }}$ Região, no AC 497870, o qual expõe:

Em sendo assim, diante de todo o exposto, encontram-se presentes os requisitos para que se determine o retorno da menor ao país de origem. O que não se pode admitir, à toda evidência, é que o fato de a criança ter se adaptado à vida no Brasil legitime seu ingresso no país e perpetue a ilegalidade de sua transferência. (AC 497870, Rel. Des. Fed. Reis Friede, Segunda Turma, julgado em 13/05/2014-, DJe 17/05/2011; ponto

\footnotetext{
15 Tradução livre: “A disposição não indica em absoluto quem deve provar esse ponto; não obstante, parece lógico pensar que essa tarefa corresponde ao sequestrador ou à pessoa que se opõe ao retorno do menor, sem prejuízo do poder de apreciação das autoridades internas a esse respeito".

${ }^{16}$ Nesse sentido, o REsp 1214408 / RJ, de relatoria do Min. Sérgio Kukina.
} 


$$
\text { n. }{ }^{\circ} 12 \text { da ementa) }
$$

O entendimento da Justiça Federal prevaleceu no sentido de que a adaptação da criança ao novo meio não pode auxiliar a atitude ilícita do genitor subtrator. Ideal esse corroborado pelo Superior Tribunal de Justiça, no Recurso Especial 1315342/RJ:

\begin{abstract}
A Convenção Sobre os Aspectos Civis do Sequestro Internacional de Crianças, ao estabelecer como uma de suas finalidades possibilitar o exercício das relações parentais dentro da legalidade e a preservação dos vínculos familiares e rechaçar qualquer atitude unilateral que possa macular o pleno exercício dessas relações, nada mais fez do que proteger os superiores interesses das crianças, preservando-lhes a dignidade que a condição humana lhes garante (REsp 1315342/RJ, Rel. Ministro Napoleão Nunes Maia Filho, primeira turma, julgado em 27/11/2012, DJe 04/12/2012; ponto n. ${ }^{\circ} 11$ da ementa).
\end{abstract}

Diferentemente, no entanto, foi a decisão tomada pelo Tribunal Federal da $1^{\circ}$ Região, analisada em sede do Recurso Especial 900262/RJ:

[...] que o pequeno $S$. encontra-se bem assistido, em sua atual residência, perfeitamente adaptado. Frequenta escola de excelente nível, convive com crianças de sua idade e desfruta da companhia dos familiares maternos, estando absolutamente amparado material e emocionalmente. Nenhum dano psíquico se imputa à guarda ora efetivamente exercida pela mãe, nem que tenha ocorrido substancial prejuízo com a alteração do domicílio para o Brasil, salvo, à toda evidência - e não pouco importante - falta do convívio paterno habitual.

Não vislumbro qualquer benefício para o pequeno S. em sua devolução aos Estados Unidos da América. Pelo contrário, nova alteração de domicílio, com separação de sua mãe, que exerce sua guarda condignamente, promoverá inequívoco abalo emocional e psíquico, que não se pode ignorar. E mais, tal providência buscada pelo Apelante divorcia-se da própria tônica em que concebida a Convenção. (Resp 900262, Rel. Min. Nancy Andrighi, Terceira Turma, julgado em 21/06/2007, DJe 08/11/2007)

A decisão proferida tomou por base a exceção prevista no artigo 12, parágrafo segundo, da Convenção, tendo sido consolidado, no julgado, o não retorno do menor aos Estados Unidos, após restar comprovado que a criança já se encontrava adaptada ao novo meio. A decisão do caso foi no sentido de que a mãe da criança, ao chegar ao território brasileiro, procurou regularizar a guarda da criança, estabelecendo medida judicial apropriada e que o "pequeno S. encontra-se bem assistido, em sua atual residência, perfeitamente adaptado".

Em contradição a decisão deferida, o Ministro Menezes Direito, proferiu seu voto de repulsa:

[...] o que estamos fazendo ao admitir que a consolidação da situação de fato, pelo tempo, impede o retorno? Estamos admitindo que qualquer pessoa possa burlar a Convenção retirando o filho, com autorização judicial, por um prazo determinado, do país de origem e aqui permanecer debaixo de um processo que pode ser moroso (Resp 900262, Rel. Min. Nancy Andrighi, Terceira Turma, julgado em 21/06/2007, DJe 08/11/2007).

No entanto, a própria Convenção da Haia de 1980, urge ressaltar, concede às 
autoridades julgadoras certo grau de discricionariedade para que decidam sobre a manutenção do menor no país de refúgio ou ordenem seu retorno ao local de residência habitual. Dessa maneira, é permitido que o órgão julgador entenda que manter a criança no Estado requerente, mesmo se comprovado que o taking parent agiu em desacordo com as regras estabelecidas na Convenção, poderá se dar em atendimento ao princípio do melhor interesse do menor, decidindo a autoridade jurisdicional, em ouvida a criança, por mantê-la na residência atual ao considerar que a ruptura com o Estado de refúgio lhe causará danos maiores.

O importante, de fato, é que tais decisões se encontrem sempre fundamentadas e subsidiadas não somente pela norma jurídica do artigo 12 da Convenção sobre os Aspectos Civis do Sequestro Internacional de Crianças, mas também façam um intercâmbio fático com estudos de ordem psicológica que possam constatar se o menor se encontra inteiramente integrado ao meio em que vive e se a mudança de domicílio poderá causar malefícios no seu futuro desenvolvimento. Tudo isso de modo a ponderar, em cada caso, se seria prudente que o impúbere vivenciasse uma nova ruptura de vínculos afetivos, especialmente em virtude de sua tenra idade ${ }^{17}$.

\section{CONSIDERAÇÕES FINAIS}

A Convenção da Haia Sobre os Aspectos Civis do Sequestro Internacional de Crianças é o principal mecanismo de combate ao rapto internacional de menores praticado por um de seus genitores. Conforme percebido na pesquisa, o fenômeno da subtração internacional de crianças cometida por um de seus progenitores é o alvo da Convenção da Haia de 1980, pois o menor não pode ser privado do contato com o genitor abandonado, do convívio cultural e do ambiente ao qual estava afeito.

O grande escopo da Convenção da Haia de 1980 é o retorno imediato do menor que fora transladado de forma ilícita de seu país de residência habitual, sem discutir o direito de guarda. Desta forma, o diploma internacional pretende restabelecer, como regra, o status quo da residência do menor para evitar possíveis danos causados à criança devido à transferência ou retenção ilícita, decorrente da perda do convívio com entes queridos após a subtração.

\footnotetext{
${ }^{17}$ Nesse sentido, o REsp 1239777/PE, de relatoria do Min. Cesar Asfor Rocha, o qual indica, em seu ponto 2, que "A Convenção de Haia, não obstante apresente reprimenda rigorosa ao sequestro internacional de menores com determinação expressa de retorno deste ao país de origem, garante o bem estar e a integridade física e emocional da criança, o que deve ser avaliado de forma criteriosa, fazendo-se necessária a prova pericial psicológica".
}

Revista Brasileira de Direito Internacional le-SSN: 2526-0219| Curitiba | v. 2 | n. 2 | p. 39 - 60 | Jul/Dez. 2016. 
Nesse diapasão, defende-se que o foro competente para discutir o fundo do direito de guarda é o local da residência habitual do menor, sob a presunção de que o juiz natural do Estado requerente possui melhores meios para avaliar as condições desse impasse. Sob essa perspectiva, referenciou-se as exceções para o não retorno do infante, por meio das situações estampadas nos artigos 12, 13 e 20 da Convenção da Haia de 1980, fundadas no princípio do melhor interesse da criança.

Ao longo do artigo, buscou-se evidenciar as exceções ao retorno imediato do menor, já que uma vez configurada a subtração ilícita, o retorno imediato do infante ao país de sua residência habitual, em algumas situações, não contempla o princípio do melhor interesse. Apesar de a regra geral da Convenção ser, como referido anteriormente, o retorno imediato do menor, é necessário, para evitar prejuízos sociais e psíquicos ao infante, que estejam configuradas e implementadas as hipóteses de exceção previstas na Convenção da Haia de 1980, especialmente quando a criança já estiver adaptada ao novo meio.

De tal modo, é possível concluir que essa Convenção, criada com a tentativa de solucionar os casos de subtração internacional de crianças, já encontra ressonância nos cenários interno e internacional, pois, antes dela, o genitor abandonado enfrentava maiores dificuldades para reaver o seu direito de guarda. Observou-se, no mais, que o termo sequestro internacional presente na tradução brasileira é equivocado, uma vez que este conceito não se refere ao termo empregado na esfera penal, já que o objetivo da Convenção é proteger a criança dos efeitos prejudiciais do translado ou retenção ilícita.

Verificou-se os requisitos para que a Convenção fosse aplicada, constatando-se que as regras estabelecidas na Convenção da Haia de 1980 somente são aplicáveis aos Estados dela signatários. Ressaltou-se que a autoridade judicial ou administrativa do Estado de refúgio não pode desconsiderar as restrições previstas nos artigos 4 e 16 da Convenção em seu exercício laboral, nem tampouco olvidar o princípio do melhor interesse da criança.

Foram abordadas também as regras de exceção ao retorno imediato do infante, pois embora a restituição seja a regra geral, as exceções a esse retorno, estabelecidas no texto da Convenção, objetivam, em cada caso concreto, uma solução mais adequada à resolução do conflito. Assim, foi observado que, no artigo 12, existe uma ressalva de adaptação do menor ao novo meio como pressuposto para a negação da ordem de retorno da criança ao país de residência habitual. Em conformidade, ficou assentada, no artigo 20, a exceção que prevê o não retorno do impúbere se houver incompatibilidade entre os princípios fundamentais do

Revista Brasileira de Direito Internacional le-SSN: 2526-0219| Curitiba | v. 2 | n. 2 | p. 39 - 60 | Jul/Dez. 2016. 
Estado de refúgio e os do Estado requerente, no que diz respeito a direitos humanos.

Notou-se que as objeções estabelecidas aos casos de rapto internacional enquadrados no artigo 13 da Convenção referem-se ao não exercício efetivo do direito de guarda pelo genitor abandonado, ao consentimento ou concordância posteriormente com a transferência ou retenção ilícita, ao risco de o menor em seu retorno ao local de residência habitual ficar sujeito aos perigos de ordem física ou psíquica e ao fato de que a criança pode se opor ao retorno, desde que esta possua idade e grau de maturidade apropriado para se expressar.

Considera-se, ademais, que embora a Convenção da Haia sobre os Aspectos Civis do Sequestro Internacional de Crianças esteja ratificada, atualmente, por noventa e quatro países, ainda existe, no Brasil, poucas discussões sobre a matéria, bem como se percebe que a morosidade em julgar tais lides faz com que, na maioria dos casos, o menor raptado e trazido para o território brasileiro acabe por se adaptar a este ambiente, constituindo uma regra impeditiva ao retorno.

Nessa pesquisa, propôs-se mostrar que esse impasse entre os progenitores da criança alvo de sequestro tende a trazer sérias consequências ao menor, em especial de ordem psíquica e social, e que o objetivo da Convenção não é nem de longe devolver a criança ao genitor abandonado ou ao seu país de origem, mas sim buscar uma resolução ao litígio de forma adequada a cada caso apresentado, à luz do princípio do melhor interesse da criança, valendo-se, para tanto, da mensuração de se o infante está adequado ao novo meio em que se encontra inserido, através de prova oral, de sua oitiva, e de perícia psicológica.

\section{REFERÊNCIAS}

ARAÚJO, Nádia de. Direito internacional privado: teoria e prática brasileira. - 5.ed. atualizada e ampliada. Rio de Janeiro: Renovar, 2011.

BRASIL. Constituição da República Federativa do Brasil, de 5 de outubro de 1988. Brasília, DF: Senado, 1988.

Decreto n. 3.413, de 14 de abril de 2000. Promulga a Convenção sobre os Aspectos Civis do Seqüestro Internacional de Crianças, concluída na cidade de Haia, em 25 de outubro de 1980. Brasília: Casa Civil, 2000.

Decreto 3.951, de 04 de outubro de 2001. Designa a Autoridade Central para dar cumprimento às obrigações impostas pela Convenção sobre os Aspectos Civis do Sequestro Internacional de Crianças, cria o Conselho da Autoridade Central Administrativa Federal contra o Sequestro Internacional de Crianças e institui o Programa Nacional para Cooperação

Revista Brasileira de Direito Internacional le-SSN: 2526-0219| Curitiba | v. 2 | n. 2 | p. 39 - 60 | Jul/Dez. 2016. 
no Regresso de Crianças e Adolescentes Brasileiros Sequestrados Internacionalmente. Brasília: Casa Civil, 2000.

Decreto n. 7.030, de 14 de dezembro de 2009. Promulga a Convenção de Viena sobre o Direito dos Tratados, concluída em 23 de maio de 1969, com reserva aos Artigos 25 e 66. Brasília: Casa Civil, 2009.

Decreto n. 99.710, de 21 de novembro de 1990. Promulga a Convenção sobre os Direitos da Criança, concluída em 2 de setembro de 1990. Brasília: Casa Civil, 1990. Civil, 1940.

Decreto-Lei n. 2.848, de 7 de dezembro de 1940. Código Penal. Brasília: Casa

Lei n. 8.069, de13 de julho de 1990. Dispõe sobre o Estatuto da Criança e do Adolescente e dá outras providências. Brasília: Casa Civil, 1990.

SUPERIOR TRIBUNAL DE JUSTIÇA. REsp 900262/RJ. Terceira Turma. Relator: Min. Nancy Andrighi. Brasília, 21 de junho de 2007. Disponível em: <http://stj.jusbrasil.com.br/jurisprudencia/8350/recurso-especial-resp-900262>. Acesso em: 8 ago 2016.

SUPERIOR TRIBUNAL DE JUSTIÇA. REsp 1196954/ES. Segunda Turma. Relator: Min. Humberto Martins. Brasília, 25 de abril de 2012. Disponível em: $<$ https://ww2.stj.jus.br/processo/revista/inteiroteor/?num_registro=201001009180\&dt_publica cao=13/03/2014>. Acesso em: 8 ago 2016.

SUPERIOR TRIBUNAL DE JUSTIÇA. REsp 1214408/RJ. Primeira Turma. Relator: Min. Sérgio Kukina. Brasília, 23 de junho de 2015. Disponível em: $<$ https://ww2.stj.jus.br/processo/revista/inteiroteor/?num_registro=201001680110\&dt_publica cao=05/08/2015>. Acesso em: 8 ago 2016.

SUPERIOR TRIBUNAL DE JUSTIÇA. REsp 1239777/PE. Segunda Turma. Relator: Min. Cesar Asfor Rocha. Brasília, 12 de abril de 2012. Disponível em: $<$ https://ww2.stj.jus.br/processo/revista/inteiroteor/?num_registro=201001807539\&dt_publica cao=19/04/2012>. Acesso em: 8 ago 2016.

SUPERIOR TRIBUNAL DE JUSTIÇA. REsp 1293800/MG. Segunda Turma. Relator: Min. Humberto Martins, 28 de maio de 2013. Disponível em: $<$ https://ww2.stj.jus.br/processo/revista/inteiroteor/?num_registro=201102678672\&dt_publica cao=05/06/2013>. Acesso em: 8 ago 2016.

SUPERIOR TRIBUNAL DE JUSTIÇA. REsp 1315342/RJ. Primeira Turma. Relator: Min. Napoleão Nunes Maia Filho. Brasília, 27 de novembro de 2012. Disponível em: <http://stj.jusbrasil.com.br/jurisprudencia/23042347/embargos-de-declaracao-no-recursoespecial>. Acesso em: 8 ago 2016.

SUPREMO TRIBUNAL FEDERAL. Convenção da Haia de 1980. Disponível em: <http://www.stf.jus.br/arquivo/cms/convencaoHaiaConteudoTextual/anexo/textoConvencao.p 
df>. Acesso em: 8 ago 2016.

TRIBUNAL REGIONAL FEDERAL DA 2ª REGIÃO. Apelação Cível 497870

2008.51.10.004697-3. Oitava Turma Especializada. Apelante: União Federal. Apelado: Fabiana Alves de Almeida. Relator: Des. Fed. Reis Friede. Rio de Janeiro, 16 de maio de 2012. Disponível em: <http://trf-2.jusbrasil.com.br/jurisprudencia/23489532/ac-apelacaocivel-ac $>$. Acesso em: 8 ago 2016.

DOLINGER, Jacob. Direito Internacional Privado. Direito Civil Internacional: A família no direito internacional privado. A criança no direito internacional. Rio de Janeiro: Renovar, 2003.

INCADAT - International Child Abduction Databas. La base de datos sobre la subtracción internacional de niños. Disponível em:

<http://www.incadat.com/index.cfm?act=text.text\&lng=3>. Acesso em: 8 ago 2016.

MIGUEL FILHO, Theophilo Antonio. Questões constitucionais e legais da Convenção da Haia sobre os aspectos civis do sequestro internacional de crianças. 2010. Tese (Doutorado em Direito) - Departamento de Direito. Pontifícia Universidade Católica do Rio de Janeiro, Disponível em: <http://www2.dbd.puc-

rio.br/pergamum/biblioteca/php/mostrateses.php?open=1\&arqtese=0621494_2010_Indice.ht ml>. Acesso em: 8 ago 2016

MÔNACO, Gustavo Ferraz de Campos; RODAS, João Grandino. A conferência da Haia de direito internacional privado: a participação do Brasil. Disponível em:

$<$ http://funag.gov.br/biblioteca/index.php?option=com_docman\&task=doc_details\&gid=29\&I temid=4 1>. Acesso em: 8 ago 2016.

PÉREZ-VERA, Elisa. Explanatory Report on the 1980 Hague Child Abduction Convention. In: Acts and Documents of the Fourteenth Session (1980), tome III, Child abduction. 1982. Versão em espanhol (Informe Explicativo). Hague: HCCH Publications, 1981. Disponível em: 〈http://www.hcch.net/upload/expl28.pdf>. Acesso em: 8 ago 2016.

SIFUENTES, Mônica. Sequestro Interparental. a experiência brasileira na aplicação da Convenção da Haia de 1980. In Revista da SJRJ, Rio de Janeiro, n. 25, p. 135-144, 2009, p. 135-144. Disponível em: < http://www.sdh.gov. br/assuntos/adocao-e-sequestrointernacional/legislacao-e-publicacoes/ sequestrointerparental-a-experiencia-brasileira-naaplicacao-da-convencao-de-haia-de-1980>. Acesso em: 8 ago 2016.

Pedido de restituição x Direito de guarda: Análise do art. 16 da Convenção da Haia de 1980. In Revista CEJ, Brasília, Ano XV, n. 55, p. 57-64, out./dez. 2011. Disponível em: <http://www.jf.jus.br/ojs2/index.php/revcej/article /viewFile/1500/1526>. Acesso em: 8 ago 2016.

TIBURCIO, Carmen; CALMON, Guilherme. Sequestro internacional de crianças: comentários à Convenção da Haia de 1980. São Paulo: Atlas, 2014. 